OPEN ACCESS

Edited by: Nora Mestorino,

National University of La Plata, Argentina

Reviewed by: Ender Yarsan,

Ankara University, Turkey Pascal Jean Jacques Sanders, Agence Nationale de Sécurité Sanitaire de l'Alimentation de l'Environnement et du Travail (ANSES), France

*Correspondence:

Jiyue Cao caojiyue2@163.com;

Qigai He

he628@mail.hzau.edu.cn

Specialty section:

This article was submitted to

Veterinary Pharmacology and Toxicology,

a section of the journal

Frontiers in Veterinary Science

Received: 19 February 2017 Accepted: 12 April 2017

Published: 01 May 2017

Citation:

Lei Z, Liu Q, Yang B, Ahmed S, Xiong J, Song T, Chen P, Cao J and He Q (2017) Evaluation of Bioequivalence of Two LongActing 20\% Oxytetracycline Formulations in Pigs. Front. Vet. Sci. 4:61 doi: 10.3389/fvets.2017.00061

\section{Evaluation of Bioequivalence of Two Long-Acting $20 \%$ Oxytetracycline Formulations in Pigs}

\author{
Zhixin Lei', Qianying Liu', Bing Yang', Saeed Ahmed', Jincheng Xiong', Tingting Song', \\ Pin Chen ${ }^{1}$, Jiyue $\mathrm{Cao}^{1 *}$ and Qigai $\mathrm{He}^{2 *}$ \\ ${ }^{1}$ National Reference Laboratory of Veterinary Drug Residues, MAO Key Laboratory for Detection of Veterinary Drug \\ Residues, Huazhong Agriculture University, Wuhan, China, ${ }^{2}$ State Key Laboratory of Agriculture Microbiology, \\ College of Veterinary Medicine, Huazhong Agriculture University, Wuhan, China
}

The aim of this study was to explore the bioequivalence of long-acting oxytetracycline in two formulations, a reference formulation (Terramycin 20\% LA, Pfizer) and a test one (Kangtekang 20\% LA, Huishen). Both formulations were administered intramuscularly at $20 \mathrm{mg} / \mathrm{kg}$ body weight at each of 24 healthy animals during a two-period crossover parallel experimental design. The oxytetracycline (OTC) concentrations in plasma were measured by high-performance liquid chromatography, and the limit of quantification was $0.05 \mu \mathrm{g} / \mathrm{ml}$ with a recovery ratio of above $90 \%$. Moreover, the descriptive pharmacokinetics parameters $\left(C_{\max }, \mathrm{AUC}_{0-144 \mathrm{~h}}\right.$, and $\left.\mathrm{AUC}_{0-\infty}\right)$ were calculated and compared under analysis of variance, and 90\% confidence interval $(\mathrm{Cl})$ were compared, except for $T_{\max }$ analyzed by non-parametric tests based on Wilcoxons's signed rank test. The comparison results of $C_{\max }, \mathrm{AUC}_{0-144 \mathrm{~h}}, \mathrm{AUC}_{0-\infty}$, and $T_{\max }$ were $5.066 \pm 0.486$, $5.071 \pm 0.877 \mu \mathrm{g} / \mathrm{ml}, 118.926 \pm 13.259,126.179 \pm 17.390 \mu \mathrm{g} \mathrm{h} / \mathrm{ml}, 123.087 \pm 13.906$, $130.732 \pm 18.562 \mu \mathrm{g} \mathrm{h} / \mathrm{ml}, 0.740 \pm 0.278,0.650 \pm 0.258 \mathrm{~h}$, respectively, and did not reveal any significant differences. In addition, $90 \% \mathrm{Cls}$ of these ratios for reference and test product were within an interval of $80-125 \%$, and the relative bioavailability of test one was $(94.291 \pm 15.287) \%$. Therefore, it has been concluded that test OTC was bioequivalent to the reference formulation in pigs.

Keywords: oxytetracycline, pharmacokinetics, bioequivalence, formulations, confidence interval

\section{INTRODUCTION}

Oxytetracycline (OTC), a broad-spectrum antibiotic, is widely used to treat Gram-positive (Streptococcus sp., Staphylococcus sp.) and Gram-negative (Escherichia coli) infections in animals (1-3). OTC is a tetracycline derivative produced by Streptomyces rimosus $(4,5)$. Long-acting oxytetracycline (LOTC) formulations are used to treat disease by maintaining an effective concentration in animals for 2 or 3 days. It is manufactured easily and used widely in developing countries as veterinary medicine (6). Long-acting injection can be performed to increase OTC and keep high concentrations in plasma above minimum inhibitory concentrations for several days, decreasing the number of administration per treatment $(7,8)$. As first LOTC receiving a market authorization, Terramycin LA (Pfizer) is the reference formulation for bioequivalence studies $(6,9-11)$.

Bioequivalence studies play an important role in new animal drug implementation and to support supplemental application in case of modification of dosage forms, administration routes, 
or manufacturing process that may have a significant effect on bioavailability $(12,13)$. Bioequivalence guidelines are established by respective organizations, while the most well-known guidelines are those of Europe and America. As a guideline to bioequivalence in the US, two products are considered for bioequivalence studies, when they are as follow bioequivalent, those in therapeutic ingredient or active ingredients, and available at the site of drug action, affected drug in assimilation rate and extent (14-18). In addition, a guideline in Europe states that bioequivalence studies should be performed within acceptable limits for the active ingredients between two products or administration routes under appropriate conditions (19-21).

According to the European medicines agency guidelines, a pharmacokinetic parameters comparison between two formulations is the best way for a bioequivalence examination of veterinary drugs, in which the area under the plasma concentration time curve to last concentration $\left(\mathrm{AUC}_{0-\mathrm{t}}\right)$, the area under the plasma concentration time curve extrapolated to infinity $\left(\mathrm{AUC}_{0-\infty}\right)$, the peak maximum plasma concentration $\left(C_{\max }\right)$, and the time to maximum concentration $\left(T_{\max }\right)$ are used for bioequivalent analysis (21). Once the bioequivalence has been demonstrated between two formulations, the clinical efficacy of test formulation is equivalent to those observed during the clinical trials of the reference formulation (22-24).

For OTC bioequivalence and pharmacokinetics studies, most investigations have been conducted in cattle and chickens, but fewer in pigs $(6,10,25-28)$.

\section{MATERIALS AND METHODS}

\section{Drugs and Reagents}

Oxytetracycline standard (96.5\%), lot number: 15820000, was used for calibration of the analytical method. Two kinds of commercial products of OTC injection containing 20\% OTC-a test one (Kangtekang 20\% LA, Huishen, lot number: 10453036AA, produced from China) and a reference one (Terramycin 20\% LA, Pfizer, lot number: 20050802, produced from America)-were selected for bioequivalence study. The other reagent used in this study was analar, purchased from Sinopharm Group Shanghai Chemical Reagent Co., Ltd.

\section{Animals}

Twenty-four landrace healthy pigs (12 males, 12 females), 6 weeks old and weighing 25-30 kg were purchased from the Livestock and Poultry Breeding Center of Hubei Province (Wuhan, China). Pigs were raised with water and antibiotic-free feed to acclimatize for 1 week prior to first drug administration. The environment temperature and relative humidity of the pig enclosure were kept at $20-26^{\circ} \mathrm{C}$ and $45-65 \%$, respectively.

\section{Bioequivalence Study Design and Sample Collection}

The bioequivalence study was performed according to a crossover design with a washout period of 8 days. Pigs were divided randomly into groups A and B of 12 pigs by groups. Pigs in group A received the test product (Kangtekang 20\% LA, Huishen) in the first period and the reference product (Terramycin 20\% LA, Pfizer) in the second period and group B received drugs in the opposite order. The two products were administered intramuscularly at a dose of $20 \mathrm{mg} / \mathrm{kg}$ body weight. All animals were bred with water and antibiotic-free feed.

Animals were sampled during the following 6 days after i.m. administrating OTC products during each period. Plasma samples $(3 \mathrm{ml})$ were collected at $0.083,0.25,0.5,1,2,3,6,8,12,24,36$, $48,72,96,120$, and $144 \mathrm{~h}$ into tubes containing heparin after i.m. administration at a single dose of $20 \mathrm{mg} / \mathrm{kg}$ body weight. Samples were centrifuged at 3,000 rpm/s for $10 \mathrm{~min}$, and then blood serum was obtained. Samples were stored at $-20^{\circ} \mathrm{C}$ until analyzed by high-performance liquid chromatography (HPLC).

\section{HPLC Determination of OTC Concentration}

A C18 reverse-phase column $(250 \mathrm{~mm} \times 4.6 \mathrm{~mm}, 5 \mu \mathrm{m}$ i.d.; Agilent, USA) was used for HPLC, which was performed with a $355-\mathrm{nm}$ detection wavelength at $30^{\circ} \mathrm{C}$. Phases $\mathrm{A}, \mathrm{B}$, and $\mathrm{C}$ were $0.01 \mathrm{~mol} / \mathrm{l}$ oxalic acid, acetonitrile, and methanol, respectively, which constituted the mobile phase of HPLC with a volume ratio (A:B:C, 83:10:7) for gradient elution. Plasma samples of $0.5 \mathrm{ml}$ were mixed with $100 \mu \mathrm{l} 10 \%$ perchloric acid with vortex oscillation at $3,000 \mathrm{rpm} / \mathrm{s}$, then extracted to obtain supernatant liquid. Supernatants were evaporated to dryness under nitrogen at $45^{\circ} \mathrm{C}$, followed by resuspension in the mobile phase at the initial volume, and then $20 \mu \mathrm{l}$ of resuspension was injected directly into the HPLC system with $0.22 \mu \mathrm{m}$ organic membranes.

\section{Pharmacokinetic and Bioequivalence Analysis}

Descriptive PK parameters were obtained with WinNonlin Professional software (Version 5.2.1) (Certara, USA). The maximum plasma concentrations $\left(C_{\max }\right)$ and time to $C_{\max }\left(T_{\max }\right)$ were obtained from the plasma concentration versus time data. AUC were calculated by the linear trapezoidal rule until the last sampling time $\left(\mathrm{AUC}_{0-144 \mathrm{~h}}\right)$ and with extrapolation to infinity $\left(\mathrm{AUC}_{0-\infty}\right) \cdot \mathrm{T}_{1 / 2}$ was calculated from the terminal slope $(\beta)$ estimated by log-linear regression according VICH guideline.

Analysis of variance (ANOVA) was used to compare and assess the effect of the formulations on the test formulation compared with the classical ones, with logarithmically transformed parameters of $\mathrm{AUC}_{0-144 \mathrm{~h}}, \mathrm{AUC}_{0-\infty}$ (Bioequivalence, August 2015) as recommended by technical guidelines for veterinary drug in China $(29,30)$. However, $T_{\max }$ comparison was performed with a Wilcoxon signed rank test. Parametric $90 \%$ confidence intervals (CIs) of the mean of test/reference ratios of $\mathrm{AUC}_{0-144 \mathrm{~h}}, \mathrm{AUC}_{0-\infty}$, and $C_{\max }$ were calculated using the residual variance of ANOVA with the assumption of a multiplicative model. CIs were calculated with SPSS analysis (IBM, USA).

\section{Statistical Analysis}

The $p$ values of $<0.05$ and $<0.01$ were considered statistically significant and extremely significant, respectively $\left({ }^{*} p<0.05\right.$ and $\left.{ }^{* *} p<0.01\right)$. 

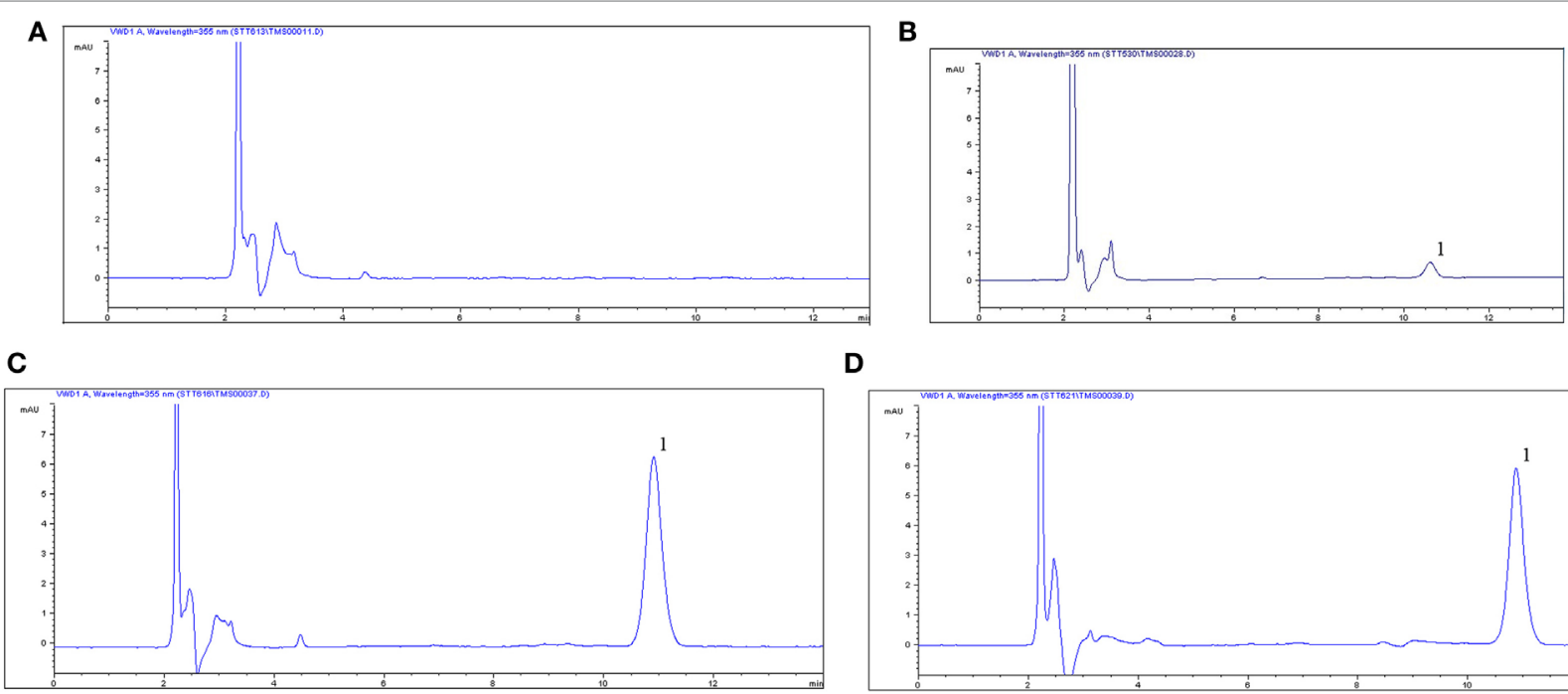

D

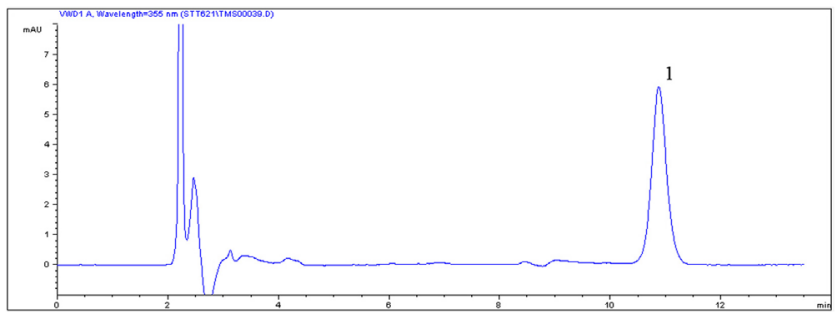

FIGURE 1 | Chromatograms of oxytetracycline (OTC) in plasma. (A) Control blank group in plasma, (B) lower limit of quantification (0.05 $\mu \mathrm{g} / \mathrm{ml})$ of OTC in plasma, (C) chromatograms of plasma at $1 \mathrm{~h}$ after i.m. 20\% OTC reference injection, (D) chromatograms of plasma at $1 \mathrm{~h}$ after i.m. 20\% OTC test one, 1, the peak time of OTC.

\section{RESULTS}

\section{OTC HPLC Analysis in Plasma}

The proposed method was suitable for OTC quantification in plasma, showing good selectivity above $89 \%$ recovery and a good linear relationship from 0.05 to $10 \mu \mathrm{g} / \mathrm{ml}$. The chromatogram in Figures 1A-D shows the blank, the lower limit of quantification (LLOQ), and measured samples at $5 \mathrm{~min}$ after i.m. of two formulation products in plasma, which indicate the proposed method for OTC detection are specific and accurate. The typical regression equation was $y=0.0507 A-0.0238, R^{2}=0.9999$. The LLOQ was $0.05 \mu \mathrm{g} / \mathrm{ml}$ in plasma presented in the Table 1 . The coefficient of determination $\left(R^{2}\right)$ of standard curves from 0.05 to $10 \mu \mathrm{g} / \mathrm{ml}$ was 0.9999 , and the inter-day and intra-day coefficient variation were below $5 \%$ in plasma. In addition, the recovery ratios were in the range of $89.13 \pm 2.54$ to $92.19 \pm 3.75 \%$ in plasma (Table 2).

\section{Pharmacokinetic Analysis}

The mean \pm SD of OTC concentration time profile are presented in Figure 2 after i.m. of two formulations, and the main descriptive PK parameters are reported in Table 3.

\section{Bioequivalence Analysis}

Log-transformed $C_{\max }, \mathrm{AUC}_{0-144 \mathrm{~h}}, \mathrm{AUC}_{0-\infty}$ and untransformed $T_{\max }$ of the test formulation (Kangtekang 20\% LA, Huishen) were compared with the reference one (Terramycin 20\% LA, Pfizer) for a bioavailability study with ANOVA analysis and 90\% CI. No statistically significant differences were observed for $C_{\max }, \mathrm{AUC}_{0-144 \mathrm{~h}}$, $\mathrm{AUC}_{0-\infty}$ in Table 3. The relative bioavailability of the test product compared to the reference one was $94.291 \pm 15.287 \%$ (Table 3).

The two one-sided $T$-tests and 90\% CI analysis displayed the ratios mean of log-transformed $C_{\max }, \mathrm{AUC}_{0-144 \mathrm{~h}}, \mathrm{AUC}_{0-\infty}$, and
TABLE 1 | Sensibility of oxytertracycline in plasma.

\begin{tabular}{lcc}
\hline Samples & LLOD $(\boldsymbol{\mu g} / \mathbf{m l})$ & Lower limit of quantification $(\boldsymbol{\mu g} / \mathbf{m l})$ \\
\hline Plasma & 0.025 & 0.05 \\
\hline
\end{tabular}

TABLE 2 | The result (mean \pm SD) of method validation of oxytertracycline in plasma.

\begin{tabular}{lcccc}
\hline $\begin{array}{l}\text { Concentration } \\
(\boldsymbol{\mu} \mathbf{g} / \mathbf{m l})\end{array}$ & $\begin{array}{c}\text { Recovery } \\
\mathbf{( \% )}\end{array}$ & $\begin{array}{c}\text { Inter-day } \\
\mathbf{C V}(\%)\end{array}$ & $\begin{array}{c}\text { Intra-day } \\
\mathbf{C V}(\%)\end{array}$ & $\begin{array}{c}\text { Accuracy } \\
\text { (RE\%) }\end{array}$ \\
\hline 0.1 & $92.19 \pm 3.75$ & $3.17 \pm 0.75$ & $3.61 \pm 0.65$ & 7.96 \\
1.0 & $90.80 \pm 2.40$ & $2.04 \pm 0.76$ & $4.07 \pm 0.86$ & 9.23 \\
10 & $89.13 \pm 2.54$ & $2.08 \pm 0.77$ & $2.43 \pm 0.78$ & 10.86 \\
\hline
\end{tabular}

$C V$, coefficient of variability, RE, the accuracy.

90\% CI on test to reference formulations were $99.5,98.8,99.1 \%$ and $91.9-107.2,99.6-100.7,92.0-102.1 \%$, which were all in the range of $75-143 \%$ within the bioequivalence acceptance range (Table 4).

\section{DISCUSSION}

As long-acting OTC belongs to the tetracycline group, it is a broad-spectrum antimicrobial agent, presenting persistent actions and sustaining absorption from the depot site after i.m. injection (26). Most studies have reported PK and bioequivalence studies in cattle, sheep, goats, and rabbits, but only a few have investigated bioequivalence in pigs $(6,11,31,32)$. In the current study, the analytical methods for OTC quantification detection in plasma were specific, sensitive, accurate and were performed for bioequivalence study between the test product and the reference one in pigs. LOQ $(0.05 \mu \mathrm{g} / \mathrm{ml})$ was available for OTC detection 

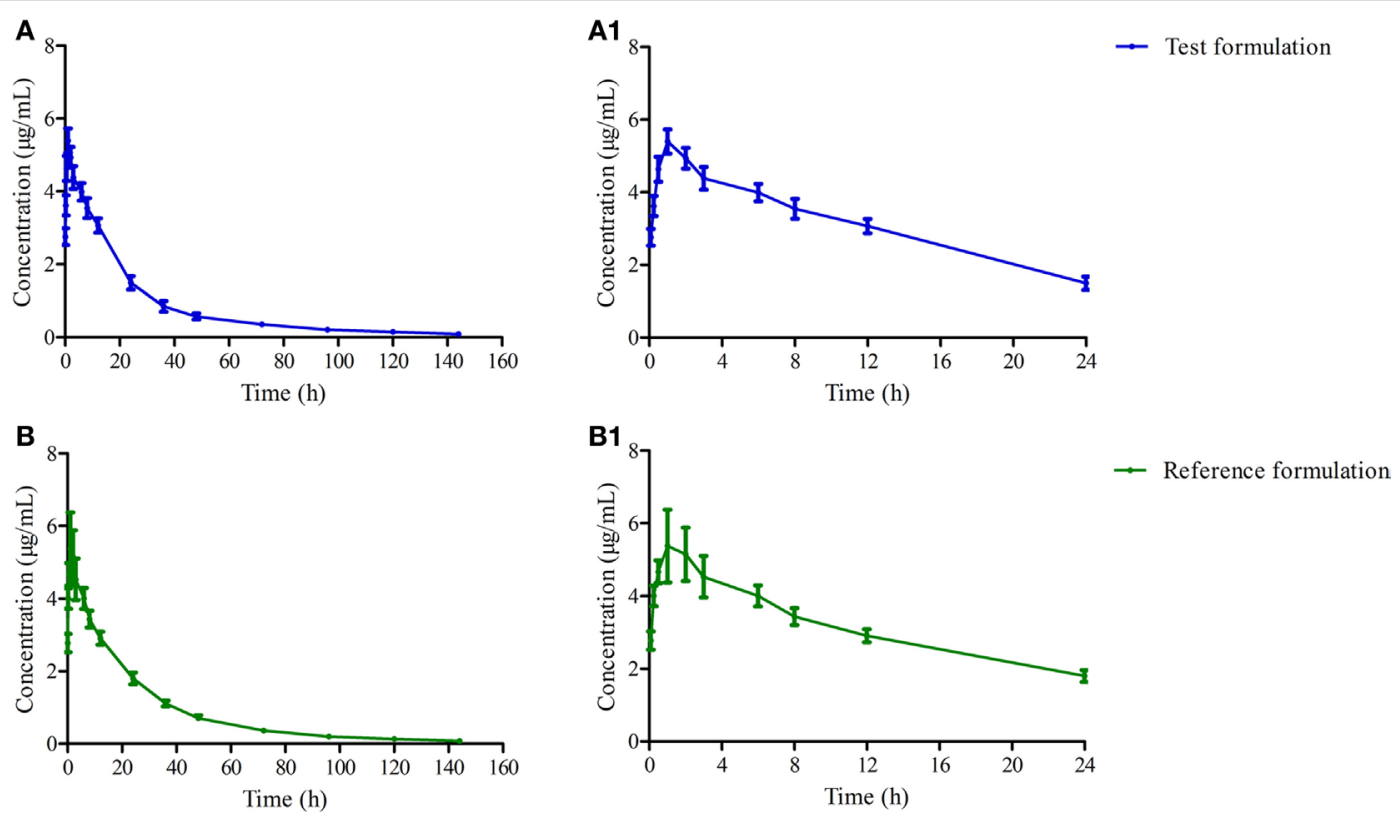

FIGURE 2 | The mean concentration time curves of test and reference formulations in plasma after i.m. (A) present the test one, $\left(A_{1}\right)$ present amplification of panel $(A)$ at 0-24 $h,(B)$ present the reference one, $\left(B_{1}\right)$ present amplification of panel (B) at 0-24 $h$.

TABLE 3 | Pharmacokinetic parameters for the test formulation and reference formulation, $p$ value and relative fraction.

\begin{tabular}{|c|c|c|c|c|c|}
\hline Parameters & Unit & Test & Reference & Analysis of variance & $F(\%)$ \\
\hline$A \cup C_{0-144 h}$ & $\mu \mathrm{g} \mathrm{h} / \mathrm{ml}$ & $118.976 \pm 13.259$ & $126.179 \pm 17.390$ & 0.976 & \\
\hline$A \cup C_{0-\infty}$ & $\mu \mathrm{g} \mathrm{h} / \mathrm{ml}$ & $123.087 \pm 13.906$ & $130.732 \pm 18.562$ & 0.313 & $94.291 \pm 15.287$ \\
\hline$C_{\max }$ & $\mu \mathrm{g} / \mathrm{ml}$ & $5.066 \pm 0.486$ & $5.071 \pm 0.877$ & 0.874 & \\
\hline$T_{\max }$ & $\mathrm{h}$ & $0.740 \pm 0.278$ & $0.650 \pm 0.258$ & $>0.05^{a}$ & \\
\hline
\end{tabular}

F represents relative bioavailability.

aWilcoxon test.

TABLE 4 | Two one-sided $T$-test and $90 \%$ of confidence interval (CI).

\begin{tabular}{lrrrcc}
\hline Parameters & \multicolumn{1}{c}{$\boldsymbol{t}_{\mathbf{1}}$} & \multicolumn{1}{c}{$\boldsymbol{t}_{\mathbf{2}}$} & $\mathbf{9 0 \%} \mathbf{C l}$ & Ratio (T/R) (\%) & $\begin{array}{c}\text { Acceptable } \\
\text { range (\%) }\end{array}$ \\
\hline AUC $_{0-144}$ & $4.928^{*}$ & 9.812 & $99.6-100.7$ & 98.8 & $80-125$ \\
AUC $_{0-\infty}$ & $6.335^{\star}$ & 8.405 & $92.0-102.1$ & 99.1 & $80-125$ \\
$C_{\max }$ & $11.486^{*}$ & 12.108 & $91.9-107.2$ & 99.5 & $75-143$ \\
\hline
\end{tabular}

${ }^{*}$ Presents significant difference $p<0.05$.

in plasma, which was similar to the one previously described $(0.05 \mu \mathrm{g} / \mathrm{ml})$ by Nora Mestorino et al. and Brentnall et al. $(6,27)$.

AUC was a useful index for biological availability of the active moiety of a drug formulation regarding the absorption extent. Both $\mathrm{AUC}_{0-144 \mathrm{~h}}$ and $\mathrm{AUC}_{0-\infty}$ were $118.976 \pm 13.259,126.179 \pm 17.390$ and $123.087 \pm 13.906,130.732 \pm 18.562 \mu \mathrm{g} \mathrm{h} / \mathrm{ml}$ for test and reference products, which are higher than previous reports in pigs (33), but the ANOVA analysis revealed these two formulations had no significant differences with $p>0.05$ (Table 3). $C_{\max }$ of these two products were similar to other reports in pigs-about $5.066 \pm 0.486$ and $5.071 \pm 0.877 \mu \mathrm{g} / \mathrm{ml}$ - which presented a high drug concentration in plasma (Table 3) (34-36). Both formulations displayed similar plasma profiles and demonstrated that they were absorbed progressively, reaching $C_{\max }$ approximately $0.75 \mathrm{~h}$ after administration, keeping $1 / 20 C_{\max }$ concentration in plasma after $120 \mathrm{~h} . T_{\max }, C_{\max }$, and $\mathrm{AUC}_{0-\infty}$ were $2.01 \mathrm{~h}, 3.98 \mu \mathrm{g} / \mathrm{ml}$, $74.87 \mu \mathrm{g} \mathrm{h} / \mathrm{ml}$, and $0.609 \mathrm{~h}, 4.956 \mu \mathrm{g} / \mathrm{ml}, 112.483 \mu \mathrm{g} \mathrm{h} / \mathrm{ml}$ in the research of Jie Bao and Xue Ling at a dose of $20 \mathrm{mg} / \mathrm{kg}$, respectively $(36,37)$. In this study, a lower peak is reached later in comparison with our results. It might be related to the OTC concentration in the drug product, which was $30 \%$ higher than the $20 \%$ in our test and reference product studied. These results suggest a slower absorption of OTC with $30 \%$ formulation in comparison with $20 \%$ ones. These parameters of OTC in this study were similar to a previous study (35). The relative bioavailability of the test product compared to the reference one was $94.291 \pm 15.287 \%$ (Table 3), and was included in the range $0.8-1.25$, which satisfied the requirements of the Food and Drug Administration (21).

For a bioequivalence study of these two OTC injection formulations, and to make a statistical comparison, $\mathrm{AUC}_{0-\text { last }}$ and $\mathrm{AUC}_{0-\infty}, C_{\max }$, and $T_{\max }$ were selected. When these parameters were not significantly different between the test and reference product, they will be bioequivalent if the CI were comparable. This was demonstrated through the ANOVA of log-transformed value and the two one-sided $T$-tests and $90 \% \mathrm{CI}$. In our study, the 
three parameters revealed there were no significant differences between the test and reference products $\left(t_{1}\right.$ and $\left.t_{2}\right)$ in $\mathrm{AUC}_{0 \text {-last }}$ and $\mathrm{AUC}_{0-\infty}, C_{\max }$, which were all above 1.717 and had significant differences $(p<0.05)$ with each other (Table 4). The $\mathrm{AUC}_{0-144 \mathrm{~h}}$ and $\mathrm{AUC}_{0-\infty}, C_{\max }$ results presenting $90 \%$ of CI were inside the CIs (75-143) set by the European Union. $T_{\max }$ presented no significant difference by non-parametric analysis (Table 4). Thus, these results demonstrated that the test OTC injection (Kangtekang $20 \%$ LA, Huishen) was bioequivalent to the reference one (Terramycin 20\% LA, Pfizer).

\section{ETHICS STATEMENT}

The animals that were used in this study were conducted according to relevant guidelines and regulations of Animal Care Center, Hubei Science and Technology Agency in China (SYXK

\section{REFERENCES}

1. Nouws JF, Vree TB. Effect of injection site on the bioavailability of an oxytetracycline formulation in ruminant calves. Vet Q (1983) 83:165-70. doi:10.1080/01652176.1983.9693891

2. Nouws JF, Vree TB, Termond E, Lohuis J, Van LP, Binkhorst GJ, et al. Pharmacokinetics and renal clearance of oxytetracycline after intravenous and intramuscular administration to dairy cows. Vet $Q$ (1985) 7:296. doi:10.1080/ 01652176.1985 .9694003

3. Mevius DJ, Nouws JF, Breukink HJ, Vree TB, Driessens F, Verkaik R. Comparative pharmacokinetics, bioavailability and renal clearance of five parenteral oxytetracycline-20\% formulations in dairy cows. Vet Q (1986) 8:285. doi:10.1080/01652176.1986.9694057

4. Coetzeea JF, Apleya MD, Kocanb KM, Rurangirwac FR, Donkersgoedd JV. Comparison of three oxytetracycline regimens for the treatment of persistent Anaplasma marginale infections in beef cattle. Vet Parasitol (2005) 127:61-73. doi:10.1016/j.vetpar.2004.08.017

5. Li RQ, Ren YW, Li J, Huang C, Shao JH, Chen XX, et al. Comparative pharmacokinetics of oxytetracycline in blunt-snout bream (Megalobrama amblycephala) with single and multiple-dose oral administration. Fish Physiol Biochem (2015) 41:803-9. doi:10.1007/s10695-015-0047-8

6. Mestorino N, Marchetti ML, Lucas MF, Modamio P, Zeinsteger P, Lastra CF, et al. Bioequivalence study of two long-acting formulations of oxytetracycline following intramuscular administration in bovines. Front Vet Sci (2016) 3:50. doi:10.3389/fvets.2016.00050

7. Banting ADL, Baggot JD. Comparison of the pharmacokinetics and local tolerance of three injectable oxytetracycline formulations in pigs. J Vet Pharmacol Ther (1996) 19:50-5. doi:10.1111/j.1365-2885.1996.tb00008.x

8. Posner LP, Burns P. Injectable anesthetic agents. Can Vet J (2009) 32:314-6.

9. Giguère S, Prescott JF, Dowling PM. Antimicrobial Therapy in Veterinary Medicine. 5th ed. New York, NY: John Wiley \& Sons, Inc (2013).

10. Mestorino N, Mariño HE, Marchetti L, Errecalde JO. Pharmacokinetics and tissue residues of an oxytetracycline/diclofenac combination in cattle. Rev Sci Tech (2007) 26:679-90. doi:10.20506/rst.26.3.1772

11. Escudero E, Carceles CM, Serrano JM. Pharmacokinetics of oxytetracycline in goats: modifications induced by a long-acting formulation. Vet Rec (1995) 135:548-52.

12. Ozdemir N, Yildirim M. Bioequivalence study of two long-acting oxytetracycline formulations in sheep. Vet Res Commun (2006) 30:929. doi:10.1007/ s11259-006-3235-2

13. Zaid AN, Mousa A, Jaradat N, Bustami R. Lornoxicam immediate-release tablets: formulation and bioequivalence study in healthy Mediterranean volunteers using a validated LC-MS/MS method. Clin Pharmacol Drug Dev (2017). doi:10.1002/cpdd.333

14. Bioavailability and bioequivalence requirements; abbreviated applications; proposed revisions - FDA. Proposed rule. Fed Regist (1998) 63:64222-8.
2013-0044). Animal housing care and experimental protocol were conducted according to the regulation of experimental animal usage in Hubei province of China, and the protocol was approved by the Ethics Committee of Huazhong Agricultural University.

\section{AUTHOR CONTRIBUTIONS}

Experiment designation: ZL, QL, JC, and QH; carrying out the experiment: ZL, BY, and JX; manuscript writing: ZL; and manuscript review and modification: SA, TS, and PC.

\section{ACKNOWLEDGMENTS}

This work was granted by Natural Science Foundation of China (no. 31272572).

15. Food and Drug Administration. Guidance for Industry Bioavailability and Bioequivalence Studies for Orally Administered Drug Products - General Considerations. Rockville (2000).

16. Chen ML, Shah V, Patnaik R, Adams W, Hussain A, Conner D, et al. Bioavailability and bioequivalence: an FDA regulatory overview. Pharm Res (2001) 18:1645-50. doi:10.1023/A:1013319408893

17. Food and Drug Administration. Bioavailability and Bioequivalence Studies for Orally Administered Drug Products - General Considerations. Rockville (2003).

18. Davit BM, Kanfer I, Yu CT, Cardot JM. BCS biowaivers: similarities and differences among EMA, FDA, and WHO requirements. AAPS J (2016) 18:612-8. doi:10.1208/s12248-016-9877-2

19. Martinez MN, Hunter RP. Current challenges facing the determination of product bioequivalence in veterinary medicine. J Vet Pharmacol Ther (2010) 33:418-33. doi:10.1111/j.1365-2885.2010.01180.x

20. Galgatte U. Study on requirements of bioequivalence for registration of pharmaceutical products in India, South Africa and Australia. Saudi Pharm J (2014) 22:391-402. doi:10.1016/j.jsps.2013.05.001

21. Kaushal N, Singh SK, Gulati M, Vaidya Y, Kaushik M. Study of regulatory requirements for the conduct of bioequivalence studies in US, Europe, Canada, India, ASEAN and SADC countries: impact on generic drug substitution. J Appl Pharm Sci (2016) 6:206-22. doi:10.7324/JAPS.2016.60430

22. Chow SC, Liu JP. Design and Analysis of Bioavailability and Bioequivalence Studies. 2nd ed. New Jersey: Berlex Laboratories, Inc (2000).

23. Chow SC, Liu J. Design and Analysis of Bioavailability and Bioequivalence Studies. 3rd ed. UK: CRC Press, Taylor and Francis Group (2008).

24. Chow SC, Liu JP. Statistical assessment of biosimilar products. J Biopharm Stat (2010) 20:10-30. doi:10.1080/10543400903280266

25. Gberindyer AF, Okpeh ER, Semaka AA. Pharmacokinetics of short- and long-acting formulations of oxytetracycline after intramuscular administration in chickens. J Avian Med Surg (2001) 29:298. doi:10.1647/2015-076

26. Brentnall C, Cheng Z, Mckellar QA, Lees P. Pharmacokineticpharmacodynamic integration and modelling of oxytetracycline administered alone and in combination with carprofen in calves. Res Vet Sci (2013) 94:687. doi:10.1016/j.rvsc.2013.01.012

27. Brentnall C, Cheng Z, Mckellar QA, Lees P. Influence of oxytetracycline on carprofen pharmacodynamics and pharmacokinetics in calves. J Vet Pharmacol Ther (2013) 36:320. doi:10.1111/jvp.12000

28. Dedonder KD, Gehring R, Tell LA, Riviere JE. Protocol for diversion of confirmed positive bulk raw milk tankers to calf ranches - a review of the pharmacokinetics of tetracyclines and sulfonamides in veal calves. Anim Health Res Rev (2016) 17(2):127-36. doi:10.1017/S1466252316000098

29. H. C. Government of Canada, Health Products, V. D. D. Food Branch. VICH guideline 52: Bioequivalence - Blood Level Bioequivalence Study (Step 4) - 2014 Health Canada Consultation Notice. Brussels (2014).

30. Pfaller MA, Andes D, Diekema DJ, Espinel-Ingroff A, Sheehan D, CLSI Subcommittee for Antifungal Susceptibility Testing. Wild-type MIC 
distributions, epidemiological cutoff values and species-specific clinical breakpointsforfluconazoleandCandida:timeforharmonizationofCLSIandEUCAST broth microdilution methods.DrugResist Updat (2010) 13:180-95. doi:10.1016/ j.drup.2010.09.002

31. Xia W, Nielsen P, Gyrdhansen N. Oxytetracyclines in cattle. A comparison between a conventional and a long-acting preparation. Acta Vet Scand (1983) 24:120.

32. Chong W, Kim YJ, Kim SD, Han SK, Ryu PD. Lack of bioequivalence of two oxytetracycline formulations in the rabbit. J Vet Sci (2002) 3:25-30.

33. Archimbault P, Navetat H, Vidal R, Douin MJ, Mignot A. Plasma bioavailability of 2 long-acting oxytetracycline formulations in the pig. Vet Res (1994) 25:399-404.

34. Cai JH, Xin GU, Liu YN. Study on pharmacokinetics of long-action oxytetracycline injection in swine. Chin J Vet Drug (2006) 40(7):17-21.

35. Hall WF, Kniffen TS, Bane DP, Bevill RF, Koritz GD. Plasma concentrations of oxytetracycline in swine after administration of the drug intramuscularly and orally in feed. J Am Vet Med Assoc (1989) 194:1265.
36. Liao XL, Zhang BX, Ding HZ. Pharmacokinetics and relatively bioavailability of oxytetracycline long acting injection in swine. Chin J Vet Drug (2012) 46(12):19-21,39.

37. Bao J. Bioequivalence and Pharmacokinetics Studies of Hydrochloride Oxytetracycline Injection in Pigs. Wuhan: China Agricultural University (2007).

Conflict of Interest Statement: The authors declare that the research was conducted in the absence of any commercial or financial relationships that could be construed as a potential conflict of interest.

Copyright (c) 2017 Lei, Liu, Yang, Ahmed, Xiong, Song, Chen, Cao and He. This is an open-access article distributed under the terms of the Creative Commons Attribution License (CC BY). The use, distribution or reproduction in other forums is permitted, provided the original author(s) or licensor are credited and that the original publication in this journal is cited, in accordance with accepted academic practice. No use, distribution or reproduction is permitted which does not comply with these terms. 